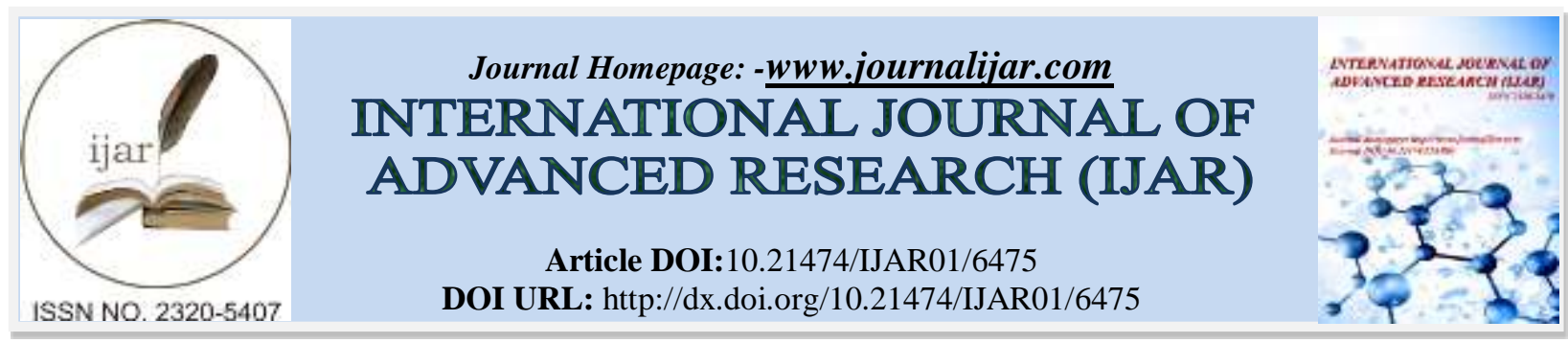

RESEARCH ARTICLE

\title{
INNOVATION DYNAMICS: A STUDY OF DIFFUSION MODEL WITH EFFICIENCY RESTRICTIONS AND POLICY MAKING.
}

Shoumik Rahman Mehedy.

Department of Electrical and Computer Engineering, North South University, Bangladesh.

\section{Manuscript Info}

Manuscript History

Received: 08 December 2017

Final Accepted: 10 January 2018

Published: February 2018

Keywords:-

Innovation Diffusion; technology

innovation; S-Curve; policy making;

Efficiency restrictions.

\begin{abstract}
Technology is the privilege. One can't simply define the future prediction if he/she doesn't give priority to the theoretical assumption rather than just doing the $R \& D$. Technology really changes over the time. Technological innovation diffusion refers to the continuous promotion and application for new technology after the earlier commercialization. The thing is like, new technology will spread and promote among the potential adopters. General model of technological diffusion explains the development of new technology diffusion by $S$ type logical curve. It is the curve that measures the improvement amounts over the time of decades or century. Dynamic model of technological innovation diffusion can be explained by Alembert principle. In this part of theorem, it is shown that diffusion speed of technology innovation is inversely proportion to the complexity of technology. Technology and innovation should run simultaneously with each other and get the potential of economic value. A Country need better policy to design the structure of management.
\end{abstract}

Copy Right, IJAR, 2018,. All rights reserved.

\section{Introduction:-}

Technology refers to the theoretical and practical knowledge, skills, and artifacts that can be used to develop products and services as well as their production and delivery systems. Technology innovation diffusion influence the economy and promote the improvement of social productive force. Although if the diffusion is in the large scale, the hole system can obtain more improvement and economical change with benefit. As new technology will come, it will bring some big changes in the market and the economic status. This type of system generally called disruptive innovation, where new market is created with network value. But this type of innovation generally too costly to afford for everyone except some selected customer. Mainly 2 main things will be working for technological innovational diffusion: the owner and the potential adopter of creative technology and media for diffusion, the channel for diffusion. The paper focused on technological innovation diffusion and technology management with current status of their position with $S$-type logical curve.

\section{Literature Review:-}

The research focused on how business policies creates opportunity and resource aspects of managerial business that defines dynamics of new firm formation in a country. We depend on Schumpeterian (4 main features of Schumpeter's theory of economic development), industrial organization economics and organizational ecological 
tradition. The paper also focused on opportunity-individual-resource model of entrepreneurial business policies. (Choi and Phan, 2004).

Evidence shows that information and communications technology(ICT), especially mobile telecommunications services, can lead to sustained economic growth and human development. The main aim of the research is modeling the diffusion of innovations for extended reach to ICT and Mobile Technologies. The key finding of this research work are country-wide socio-economic and endogenous cultural drivers, such as risk and uncertainty avoidance. Well-targeted subsidies in the early stages of ICT diffusion can play a determinant role in their massive diffusion, helping to overcome initial confidence barriers, leveraging economies of scale and in long-term process, triggering macroeconomic positive feedback mechanisms. (Dahan,2011)

The enterprise technology innovation diffusion starts from application of commercialized invention or achievement, is connected with the whole commercialized process of technology. Technology innovation diffusion is blessing for all kinds of situation. Meanwhile, it's efficiency is restricted by market competition intensity, cost of technology innovation, revenue of technology innovation, enterprise learning ability. (Yonglong and Minjie, 2011).

A theoretical framework has been proposed to study patterns of innovation diffusion in a heterogeneous population, with applicability to a number of problem areas including marketing. The effect of heterogeneity leads to the generation of bi-modal life cycle patterns besides the conventional uni-modal pattern resulting from S-shaped curve. The stochastic evolution of the mean and variance of the number of adopters is found to depict a high level of relative fluctuation around the point of inflexion. For demonstrating the effectiveness of the proposed framework, a real data set which depicts a bi-modal life cycle curve is investigated. The fit is found to be extremely good while capturing appropriate product life cycle curve. (Karmeshu and Goswami,2001)

The authors modeled the spread of a new technological item in a population through novel network dynamics where diffusion is based on the word-of-mouth and the persuasion strength increases the more the product is diffused. In this paper we carry on an analysis on large scale graphs to show off how the parameters of the model, the topology of the graph and, possibly, the initial diffusion of the item, determine whether the spread of the item is successful or not. The paper is completed by a number of numerical simulations with analytical results. (Fagnani and Zino,2017)

All of the research papers basically focused on the innovation diffusion with various effects on products as well as on the customers. The network between the customers and the technology with their fruitful effect and how some problems can be solved. ICT application in the technology innovation with the modeling of their services and create economic status for the country.

This paper focused on simulation of technological innovation diffusion with dynamic model and show some methods of innovation management with working process and $S$-type logical curve to show their current position of improvement and some policy between customer and producer.

\section{Technological Innovation Diffusion:-}

Well, it is clear that enterprises create great economic opportunities and values. They imply a solid impact on the foundation of domestic as well as international wealth. The real life working application of knowledge and interdevelopments depend on individuality with the enterprises and the transfer of knowledge as well as the skills into production force, products, service, market and employment. The enterprises are not the only one who can get the credit to be the main investors in the sector of technological innovation. It is the winner or on the other way, it is the gainer who wins the opportunities and hit to the strike gold from innovation on Science and technology. In the running development countries, enterprises are in the movement for investing almost 60 to 70 percent of funds for their R\&D. in the developed country, the ratio is much higher than others.

Now coming to the other part, consider the viscidity of technological innovation of enterprises depends on how complex the technology of innovation is. It is obvious that a complicated technology can only be understood by only certain level of people. Therefore, it is difficult for information on technology to flow. These kinds of characteristics can be verified by $S$-type logical curve. When there is investment, the factor that comes first priority is the risk. It is the product of maximum loss of the failure of innovation diffusion as well as the probability of failure. (Wei, 2008) 
At the time when risk and the complexity of technology for innovation of enterprises are same, the technological innovation diffusion of enterprise will be balanced. However, the speed of technological innovation diffusion is not even at all because of the restriction of intellectual property rights protection and transaction cost. The capability for each enterprise to absorb innovation diffusion is also different. As a result, inner friction force of technology innovation emerges in the process of diffusion. (Wei, 2008)

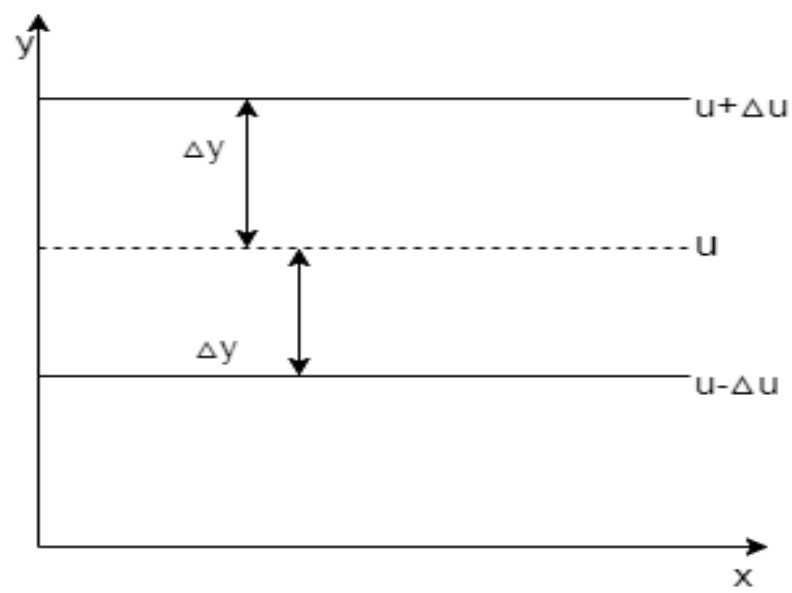

Fig.01:- Chart of technological innovation diffusion.

On the upper layer from $\mathrm{u}$, the innovation for technology is complex. On the other hand, lower level from $u$ is simpler. So the situation of the complexity of two positions is different. Here, $\Delta \mathrm{y}$ is very small and tiny in volume as only the professionals can diffuse the technological information effectively. But frankly speaking, Technological innovation diffusion among enterprises is only related to the speed distribution of diffusion. It is indicating that it is up to the part grade of speed $\mathrm{u}^{\prime}$ or $\mathrm{du} / \mathrm{dy}$. As for smaller $\mid \mathrm{du} / \mathrm{dy}$. We can assume that the relationship between the tangential of diffusion pressure and the speed gradient $\mathrm{du} / \mathrm{dy}$ is linear type. It will show the result that $\tau_{x y}=\mu \frac{d u}{d y}$

In the formula (1), $\tau_{\mathrm{xy}}$ denotes the pressure of technological innovation diffusion in enterprise, $\mu$ is the coefficient. (Wei, 2008)

\section{Dynamic Model of Technological Innovation Diffusion:-}

At the time, when diffusion resources spreads around, technology innovation is always carried out along diffusion axis with higher comprehensive quality, then spreads in regions of axis. Technology innovation diffusion is different in space in practice. We pick up a parallel differential hexahedron with the sides of dx, dy, dz. Three batches of technological innovation diffusion are operated on each surface. By the application of Alembert principle, we can build up the balance equation of technological innovation diffusion:

$\delta W=\sum_{x} F_{x} \cdot \delta s_{x}=0 \quad$ (2) or in the simplest form

$\sum F_{x, i}=0$

here on equation (2) $\delta s_{x}$ is virtual displacement in one dimensional direction.

D' Alembert principle is just the principle of virtual work with the inertial force added to the list of forces that do work. It represents one dimensional wave equations. So if we consider as 3 dimensional workspaces, then the propose work should be:

$\sum F_{x, i}=0, \sum F_{y, i}=0, \sum F_{z, i}=0$

here, i also represents the virtual displacement.

That is,

$$
\left(P_{x, x}+\frac{\partial P_{x, x}}{\partial x} d x\right) d y d z-\left(P_{x, x} d y d z+\frac{\partial \tau_{y, x}}{\partial x} d y\right) d x d z-\tau_{z, x} d x d y+x \rho d x d y-\frac{d v_{x}}{d x} \rho d x d y d z=0
$$


By simplify formula (4) and forming $d x, d y, d z \rightarrow 0$, we can get the first and another formulas according to the same principle:

$\frac{d v_{x}}{d t}=X+\frac{1}{\rho}\left(\frac{\partial p_{x, x}}{\partial x}+\frac{\partial \tau_{y, x}}{\partial y}+\frac{\partial \tau_{z, x}}{\partial z}\right)$

$\frac{d v_{y}}{d t}=Y+\frac{1}{\rho}\left(\frac{\partial \tau_{x, y}}{\partial x}+\frac{\partial p_{y, y}}{\partial y}+\frac{\partial \tau_{z, y}}{\partial z}\right)$

$\frac{d v_{z}}{d t}=Z+\frac{1}{\rho}\left(\frac{\partial \tau_{x, z}}{\partial x}+\frac{\partial p_{y, z}}{\partial y}+\frac{\partial \tau_{z, z}}{\partial z}\right)$

By multiplying among the equations (5), (6) and (7) with $\vec{\imath}, \vec{\jmath}, \vec{k}$ and summarize the result:

$\frac{d \vec{v}}{d t}=\vec{F}+\frac{1}{\rho}\left(\frac{\partial \vec{\rho}_{x}}{\partial x}+\frac{\partial \vec{\rho}_{y}}{\partial y}+\frac{\partial \vec{\rho}_{z}}{\partial z}\right)$

In the formula (8), $\rho$ is called coefficient of technology diffusion. $\vec{F}$ is called viscidity of diffusion ( 3 dimensional with combinational result as $\mathrm{XYZ}=\vec{F}$ ). So the diffusion speed of technology is inversely proportional with the complexity of technology with viscidity of diffusion.

\section{Dynamic Equilibrium:-}

$\mathrm{D}^{\prime}$ Alembert's form of the principle of virtual work states that a system of rigid bodies is in dynamic equilibrium when the virtual work of the sum of the applied forces and the inertial forces is zero for any virtual displacement of the system.

$\frac{d}{d t} \frac{\partial T}{\partial q_{j}}-\frac{\partial T}{\partial q_{j}}=Q_{j} \quad j=1,2 \ldots . . n$

Technology $S$ - Curve:-

It will be described as the description of the magnitude of improvement of a similar technology or any other thing.

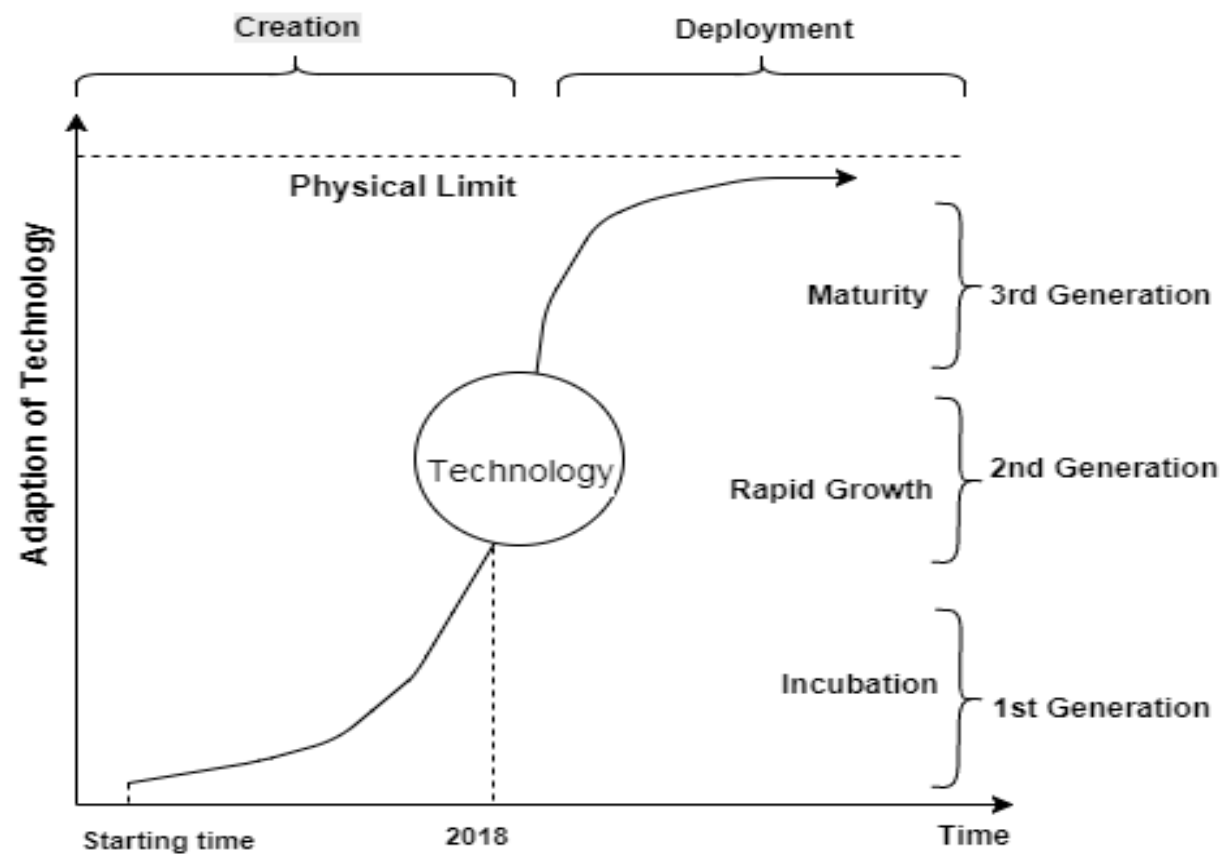

Fig.02:- Technology Innovation Diffusion $S$ Curve.

From the early staring time to until now 2018, Technology innovation has been changed tremendously. Basically it takes some time and effort to pass a technology from the first generation. $2^{\text {nd }}$ generation passes rapidly and effectively. When a technology s-curve reaches to its pinnacle point of destiny or more likely to say grabs it's top 
point or $3^{\text {rd }}$ generation, that means the product or the technology cannot see any new innovation or produce any new things rather than just re-manufacture it again and again with a new look have almost nothing new from before.

Just like i phone which is already free-fall in china. For example, people in the last 5 or 7 years ago were very much keen to know about the resolution of the camera. They liked to know how high much technology the company has bring to them in efficient price.

Maturity Level:- Technology Innovation Diffusion

\section{Characteristics of the Maturity levels}

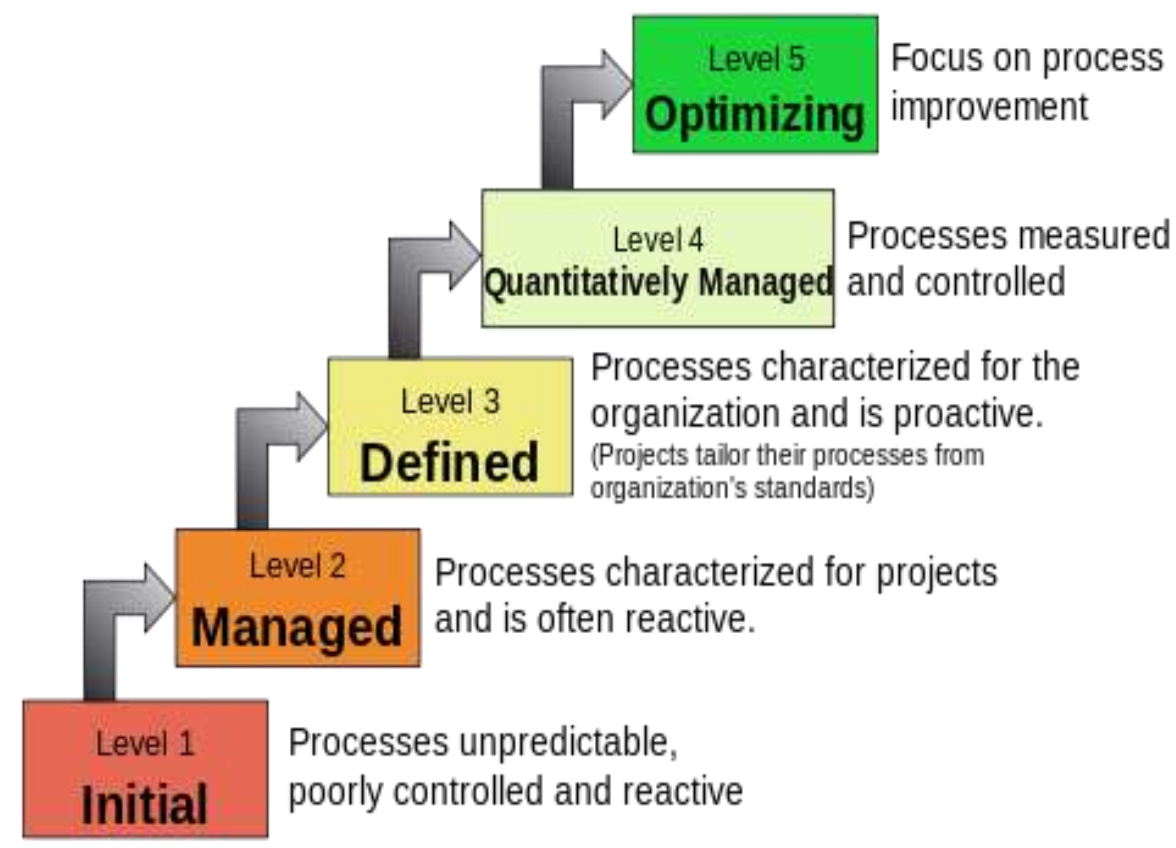

Fig.03:- Maturity Level of Technology Innovation Diffusion.

\section{Technology Innovation Diffusion: Within Technology Management System:-}

Technology management is a link among engineering, science and management disciplines to plan, develop and implement technological capabilities to shape and accomplish the strategic and operational objectives of an organization. For having the ability to compete in technology management system is Cost, Quality, Time to deliver, Predictability, Scale, Continuous improvement. Now management is very important to keep the pace in the market to fulfil the target work. Technology management have not such kinds of effect on innovation. But it has a large system of integrity to manage the property of technology innovation diffusion and the environment.

Well, there are some typical concepts in technology management like Technology strategy, technology forecasting and technology roadmap. Continuous development, acquisition, and deployment of technology is valuable as long as there is a value for the customer and therefore the technology management function in an organization should be able to argue when to invest on technology development and when to withdraw. The basic structure of Technology innovation diffusion fits with the management to maintain the balance for a long run: 


\section{Man/ Women}

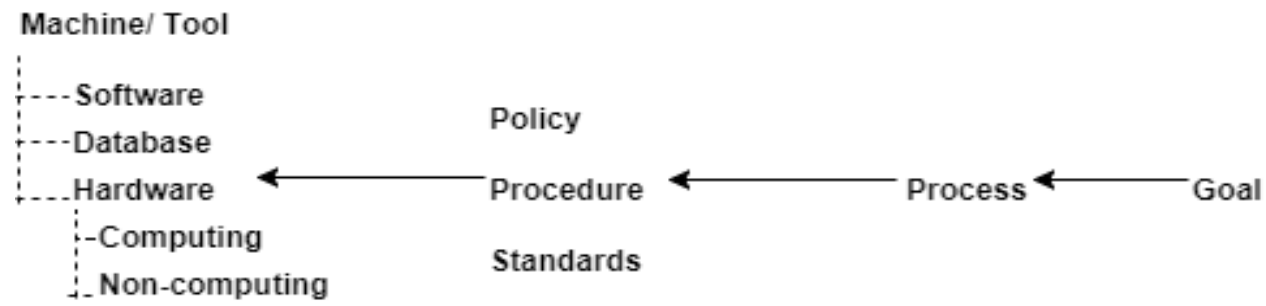

\section{Communication Network}

Fig.04:- Technology Innovation diffusion management system

Working Process In Technology Organization: Some Policy:-

Coming to this point, there emerge some technical issues. Here are basically 7 steps for technology organization or any kinds of management in the field of technology.

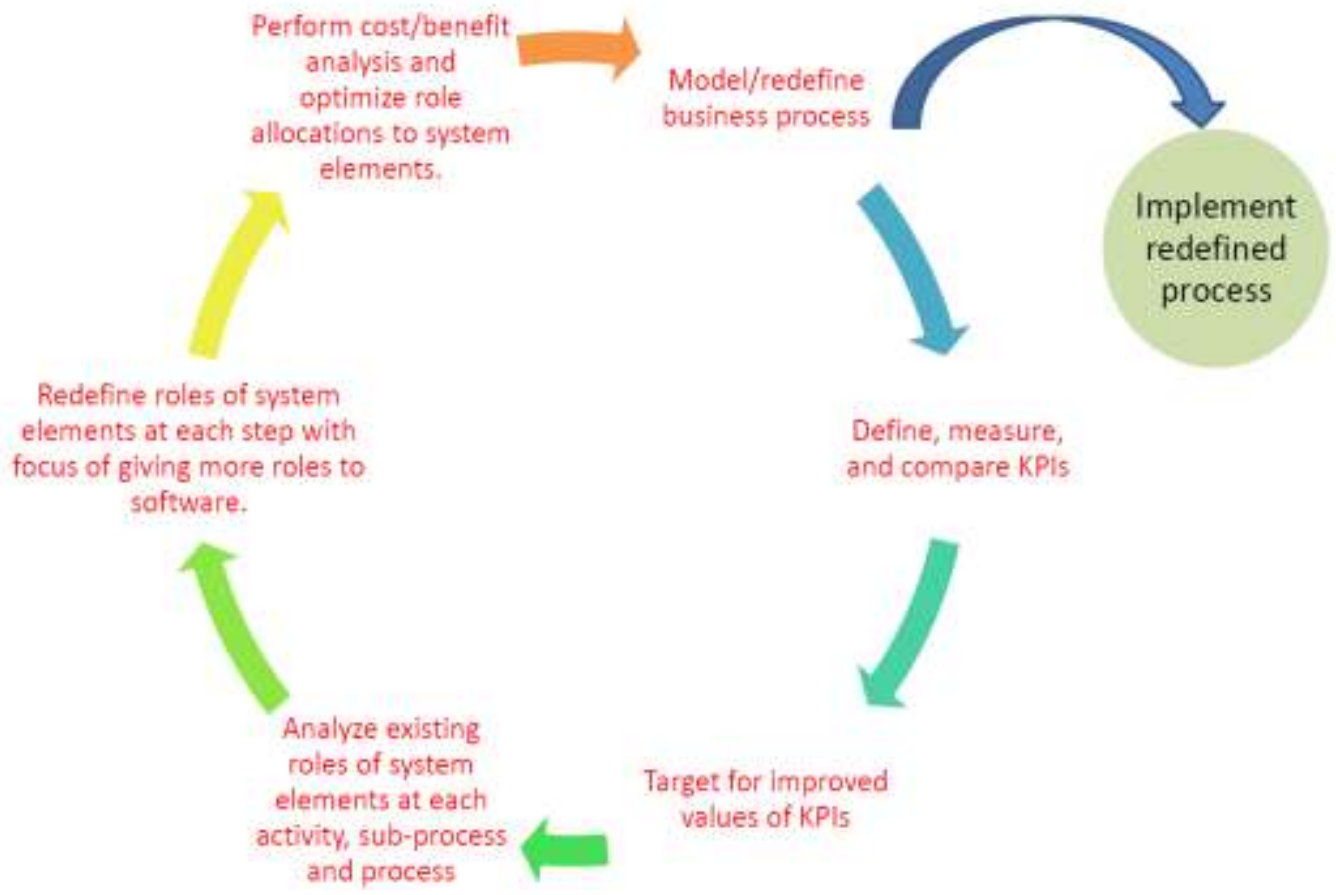

Fig.05:- Working Process Flow chart in Technology Organization.

Key Performance Indicator (KPI) is a specific measure of an organization's performance in an area of its business. The Harsh reality is, people and all other companies or organizations only want to see the result of the effort. They will see the result of the technology. That's why result part has been thrown out of the circle. I mean, it is obvious, no one will ever want to invest or fund money for the six process the circle. They will never keen to know how hardship has been passed to build the innovative technology. People expect all the work should be done by one category of people.

This seems really preposterous. The University graduates and vocational school graduates must have the difference. It is the duty of vocational school graduates to implement any project by proper direction. And that direction must be made by university graduates. But frankly speaking, it is not really necessary to be a university graduate to set the 
policy. Inner integrity and potential make them big. But vocational knowledge should be adopted to implement the directions.

\section{Efficiency Restrictions of Enterprise Technology Innovation Diffusion:-}

There are basically 3 efficiency restrictions of enterprise technology innovation diffusion.

\section{Industry Competition Intensity:-}

For a long time, it was really a point of argument that different market situation has individual competition intensity of their own. That's why every market situation has its own demand characters. A well-established perfect market competition always maintains an elastic demand supply. So by this argument, it is clear that with a lower unit cost technology innovation will substitute old technology within a time. Higher Productivity will always meet the demand of low unit cost and maximum profit.

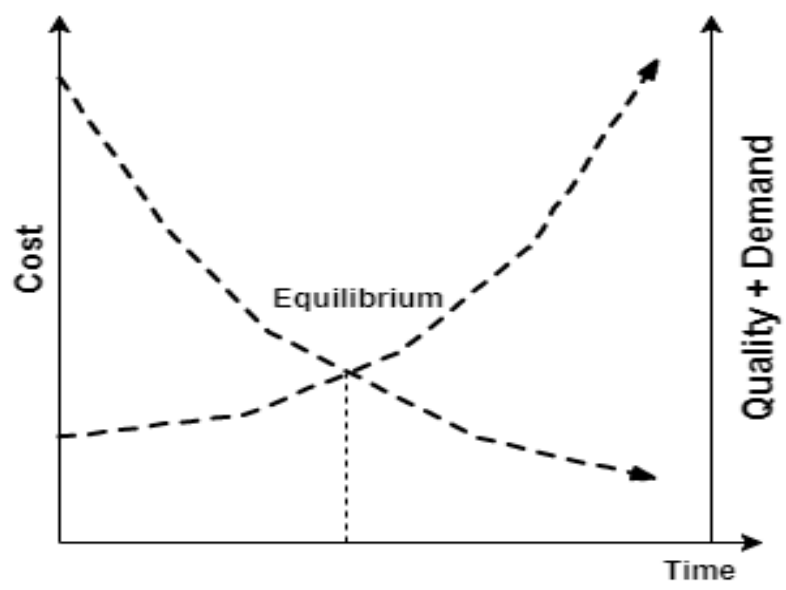

Fig.06:- Cost-Demand Curve.

However, Because of the certain degree of monopoly, information asymmetry and technology differences, real market is always an impact competition market which leads to market liquidity weakness and prevent technology innovation diffusion as well. Truly speaking, Technology innovation diffusion across industry is relative to industry competition intensity directly. With that saying, it is proportional to the number of enterprises and potential technology adopters, inversely proportional to degree of technology monopoly and proportional to industry average growth rate. (Yonglong and Minjie, 2011)

\section{Enterprise Structure of Resource-Technology:-}

It will be bogus saying and practically not possible for an enterprise to have every individual competitive resource. It will focus on some region of problems and try to overcome the lacking of their innovative product that has to catch the consumer and make a stable position in the market. Because no matter how good innovator you are, how good your technology is, if you can't spin the money flow, if you can't see the future, you will be bankrupted. 


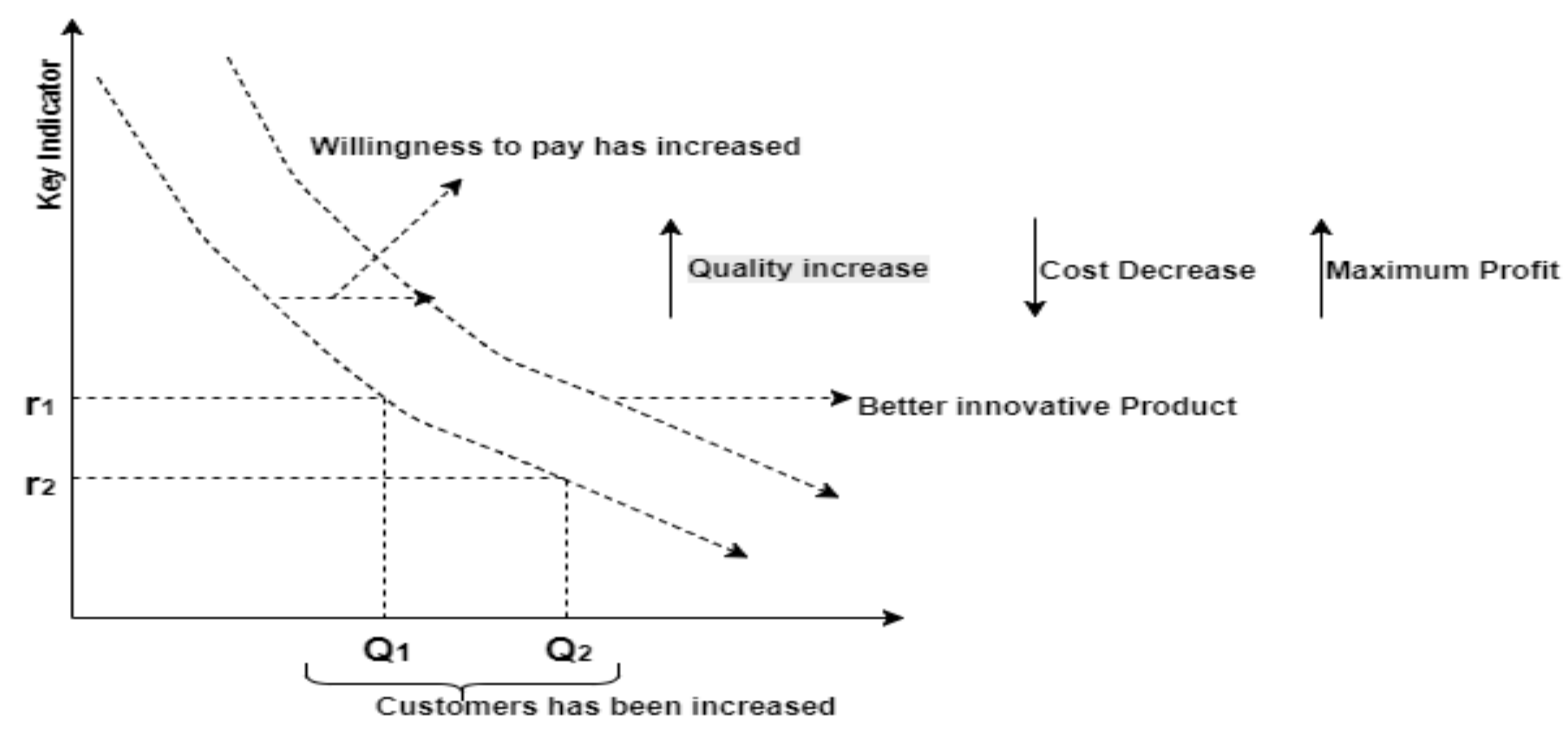

Fig.07:- Consumer/ Customer status and willingness curve

Technology change is a process of dynamic evolution, while technology application is creative activity depending on experiments, study and access to the relevant information.

\section{Enterprise Ability of Learning Technology:-}

Any enterprise can't get success by only learning the previous knowledge and technology. They have to make pace to pace with the generation and their needs. They have to apply the process and ability of new technology. One thing must be remembered that subconscious mind learns and innovate far better than conscious mind. Learning and adopting knowledge should be open.

Creating new wealth out of technology and innovation has been the only opportunity for us to create growing wealth out of depleting resources of this planet--to meet the increasing consumption of fellow human beings. Although we admire innovators and inventors for the success of innovation, but hardly we analyze diverse policies issues, apart from the policy of S\&T education and $R \& D$ investment, affecting the innovation journey. Technology and Innovation do not work in isolation of broader underlying policies, guiding the society at various levels--eventually shaping the possibility of wealth creation and growth. (zaman, 2017)

\section{Acknowledgement:-}

Really Thankful to my loving and respected Professor Dr. Rokonuzzaman (Rokon Zaman), (Ex-Dean, School of Engineering and Physical Science, North south University, Bangladesh and country's one of the top most IT specialists) whose class lectures and written book (Technology, Innovation and Policy Views: A compendium of opeds, from the perspective of Bangladesh and other developing countries (TIPViews Book 1) [Print Replica] Amazon Kindle Edition) as well as other one book motivated enough to research and have much interest on Innovation Dynamics with entrepreneurship and information Technology topics.

\section{Conclusion:-}

The process of technological innovation diffusion involves plenty of active and uncertain factors. It is actually a complex non-linear system. The key question for it to answer and solute is how to speed up technological innovation diffusion and get more benefit from it. Many people came to win or wiped out into the lack of proper integration of work and system. Innovation and success has to meet each other. Otherwise people will not have the positive effect of that innovation technology. Innovation technological diffusion plays a vital role in the economy, culture and serve the humanity to make like easier. 


\section{References:-}

1. Choi, Y. R. and Phan P. H. (2004) Dynamics of New Firm Formation: Impacts of Economic and Technology Policy. In: Engineering Management Conference, Singapore 2004. IEEE, 703-707.

2. Dahan, M. (2011) Modeling the Diffusion of Innovations for Extended Reach to ICT and Mobile Technologies. In: IEEE Global Humanitarian Technology Conference, USA 2011. IEEE, 393-397.

3. Yonglong, W. and Minjie, Y. (2011) The Analysis on Mechanism of Enterprise Technology Innovation Diffusion and its Efficiency Restrictions. In: 2nd International Conference on Artificial Intelligence, Management Science and Electronic Commerce (AIMSEC), China 2011, IEEE.

4. Karmeshu and Goswami, D. (2001) Stochastic evolution of innovation diffusion in heterogeneous groups: Study of life cycle patterns. In: IMA Journal of Management Mathematics, 12(2), 107-126.

5. Fagnani, F. and Zino, L. (2017) Diffusion of Innovation in Large Scale Graph. In: IEEE Transactions on Network Science and Engineering, 4(2), 100-111.

6. Wei. H. (2008) A study on Viscidity and Dynamics Model of Technological Innovation Diffusion. In: International Seminar on Future Information Technology and Management Engineering, UK 2008, IEEE, 342345.

7. Zaman, R. (2017) Technology, Innovation and Policy Views: A compendium of op-eds, from the perspective of Bangladesh and other developing countries. Amazon, Kindle edition.

8. Chinn, M.D. and Fairlie, R. W. (2006) The determinants of the global digital divide: a cross-country analysis of computer and internet penetration. Yale University: Oxford Economic Papers.

9. Sterman, J. D. (2000) Business Dynamics: Systems Thinking and Modeling for a Complex World. Irwin/ McGraw-Hill,2000.

10. Schumpeter J. A. (1934) The Theory of Economic Development: An Inquiry into profits, Capital, Interest, and the Business Cycle. Cambridge, MA: Harvard University Press, 1934. 